\title{
Oxidative Stress in Liver of Streptozotocin Induced Diabetic Rats: Ameliorating Role of Aegle Marmelos Leaf Extract
}

\author{
Manju $\mathbf{T}^{1}$, Anju T $\mathbf{R}^{* 1}$ \\ ${ }^{1}$ Molecular Neurobiology and Cell Biology Unit, Centre for Neuroscience, Department of Biotechnology, Cochin \\ University of Science and Technology, Cochin-682022, Kerala, India \\ Email: biomncb@cusat.ac.in
}

\begin{abstract}
Hepatic tissue damage mediated through altered antioxidant defence is one of the characteristic features of diabetes. Phytotherapy using Aegle marmelos leaf extract has been reported to control diabetes complications on brain functions. The present study was carried out to evaluate whether the anti-hypergycemic effects of Aegle marmelos leaf extract can regulate diabetes related hepatic oxidative stress. To understand this, antioxidant and peroxide levels and expression of stress related Hypoxia inducible factor 1 (HIF 1) mRNA were analysed in liver tissue of experimental rat models. The decreased total antioxidant level with elevated peroxide level along with upregulation of HIF 1 gene expression indicates poor oxidative defenses in the liver of diabetic rats. These altered parameters were reversed to near control level by Aegle marmelos treatment which indicates that Aegle marmelos can not only regulate blood glucose levels but also control diabetes related hepatic complications.
\end{abstract}

Keywords: Reactive oxygen species; antioxidants; free radicals; hyperglycemia; HIF-1 $\alpha$

\section{Introduction}

Diabetes mellitus has become a serious health issue characterized by hyperglycemia and metabolic disturbances with absolute or relative deficiency in insulin secretion or insulin action [1]. Reactive oxygen species (ROS) are produced in the cells under various conditions especially when glucoregulation is compromised as in the case of hyper/hypoglycemia. Previous study reported the generation of ROS under hyperglycaemic condition, ultimately leading to increased oxidative stress [2]. Oxidative stress is an increase in the steady state levels of reactive oxygen species and occurs as a result of increased free radical generation, decreased antioxidant defense mechanisms, or both [3]. Oxidative stress is reported to have a significant effect in the causation of diabetes as well as diabetes related complications in human beings [4]. Oxidative stress in diabetes has been revealed to co-exist with a reduction in the antioxidant status [5]. Other circulating factors that are elevated in diabetics such as free fatty acids and leptin also contribute to increasing reactive oxygen species [6]. There is increasing evidence that free radical induced damage also plays a significant part in the development of insulin resistance, $\beta$-cell dysfunction, impaired glucose tolerance, and type 2 diabetes mellitus [7].

In diabetes hyperglycaemia, protein glycation and glucose auto oxidations have been suggested to induce free radical generation [8] which can modulate the expression of hypoxia-inducible factor- $1 \alpha$ $(\mathrm{HIF}-1 \alpha)$, a transcription factor in the cellular adaptive response to hypoxic conditions. Hyperglycemia augments oxidative stress and induces the overproduction of ROS [9], which modulates HIF-1 $\alpha$ regulation. The effect of hyperglycemia on HIF-1 through the action of ROS is complicated and diverse $[10,11,12]$. Adaptation occurs as a response to oxidative stress and involves up regulation of the synthesis of components in the antioxidant defence system, such as antioxidant enzymes and molecules. As liver plays a major role in the carbohydrate metabolism, diabetes results in severe alterations in hepatic functioning. Impeded liver metabolism leads to the impairment of homeostasis and increases the predisposition to liver diseases [13] (Papaccio et al. 2000). Since liver is a major organ attacked by ROS [14], understating oxidative stress in liver during diabetes is important in dealing with diabetes related complications.

Aegle marmelos extract, which is being used in the traditional medicine to reduce the serum glucose level, has significant antioxidant activity in vitro [15]. Aegle marmelos is being used for thousands of 
years as a traditional medicine for the treatment of diarrhoea, dysentery, peptic ulcers, skin and eye diseases. Aegle marmelos leaf extract can significantly control the blood glucose, urea, body weight, liver glycogen and serum cholesterol $[16,17]$. Histological observations in pancreatic, liver and kidney tissues in Aegle marmelos treated diabetic rats indicate the hypoglycaemic potential of the extract [18]. Since Aegle marmelos leaf extract is well proven alternate therapy for diabetes with potentials in protecting brain neurotransmitter pathways and pancreatic function, it might have an ameliorating role in diabetes induced liver damage too. The present study focused on the use of phytotheraputics for the control of diabetes related hepatic complications. It is more relevant in the light of recent studies showing incidence of hepatotoxicity of current diabetes medications. The present study was undertaken to evaluate the protective effect of Aegle marmelos leaf extract on the antioxidant defence system in the liver of Streptozotocin -induced diabetic rats.

\section{$2 \quad$ Materials and Methods}

\subsection{Animals}

Male wistar adult rats (200-250 g) were purchased from Amrita Institute of Medical Sciences, Cochin and used for all experiments. They were housed in separate cages under 12 hours light and 12 hours dark periods and were maintained on standard food pellets and water ad libitum. All animal care and procedures were in accordance with Institutional and National Institute of Health guidelines.

\subsection{Preparation of Aegle Marmelos Leaf Extract}

Fresh leaves of Aegle marmelos plant were air dried in shade and powdered. $10 \mathrm{~g}$ of leaf powder was mixed with $100 \mathrm{ml}$ of distilled water and stirred for $2 \mathrm{hr}$. It was kept overnight at $4^{\circ} \mathrm{C}$. The supernatant was collected and evaporated to dryness followed by lyophylization in Yamato, Neocool, Japan lyophilizer. This was used as the crude leaf extract to study the anti-diabetic effect in streptozotocin induced diabetes.

\subsection{Induction of Diabetes}

The animals were randomly divided into control $(\mathrm{C})$, diabetic (D), diabetic treated with insulin (DI) and diabetic treated with Aegle marmelos (DA). Diabetes was induced by a single intrafemoral dose (55 $\mathrm{mg} / \mathrm{kg}$ body weight) of Streptozotocin prepared in citrate buffer, $\mathrm{pH} 4.5$. The DI group received a daily dose (1 Unit $/ \mathrm{kg}$ body weight) of Lente and Plain insulin. Aqueous extract of Aegle marmelos was given orally in the dosage of $1 \mathrm{~g} / \mathrm{Kg}$ body weight at 24 hour intervals.

The experimental rats were sacrificed by decapitation after 15 days treatment. The liver was dissected out quickly over ice. The tissues were stored at $-80^{\circ} \mathrm{C}$ until assay. Glucose was measured by GOD-POD glucose estimation kit (Biolab Diagnostics Pvt. Ltd).

\subsection{Estimation of Blood Glucose Concentration}

Blood glucose was estimated by spectrophotometric method using glucose oxidase-peroxidase reaction. Blood samples were collected from the tail vein at $0 \mathrm{~h}$ (before the start of the experiment), 3rd, 8th, 12 th and 15th day, and the glucose levels were estimated subsequently. Along with this, blood samples were collected $3 \mathrm{~h}$ after the administration of a morning dose. The results were expressed in terms of milligramme per deciliter of blood.

\subsection{Protein Determination}

Protein was measured by the method of Lowry et al., 1951 [19] using bovine serum albumin as standard. The intensity of the purple blue color formed was proportional to the amount of protein which was read in Spectrophotometer at $660 \mathrm{~nm}$. 


\subsection{Antioxidant Assay in the Cerebral Cortex of Experimental Groups}

The total antioxidant capacity of cerebral cortex was analyzed according to the protocol of antioxidant assay kit by Sigma, Saint Louis, USA. The concentration of total antioxidant was expressed in nanomolar. For all experimental groups, the incubation mixture contains $0.1 \mathrm{mg}$ protein in each assay.

\subsection{Peroxidetect Assay for Determination of Hydroperoxides in the Cerebral Cortex of Experimental Groups}

The measurement of peroxides in the cerebral cortex was estimated according to the protocol of peroxi Detect kit by Sigma- Aldrich, Saint Louis, USA. For aqueous peroxides, standard curve was plotted with nmoles of $\mathrm{H}_{2} \mathrm{O}_{2}$ against $\mathrm{A}_{560}$ and for organic/ lipid peroxides, standard curve was plotted with nmoles of tert- Butyl hydroperioxide against $\mathrm{A}_{560}$. The nmoles of peroxide in the test sample was calculated as below:

$$
\text { nmole peroxide } / \mathrm{ml}=\frac{[\mathrm{A} 560(\text { sample })-\mathrm{A} 560(\mathrm{blank})] \mathrm{X} \text { dilution factor }}{[\mathrm{A} 560(1 \mathrm{nmole} \text { peroxide })] \mathrm{X} \text { sample volume }}
$$

\subsection{Real -Time PCR Assay}

RNA was isolated from the liver of experimental rats using the Tri reagent (Sigma, USA). Total cDNA synthesis was performed using ABI PRISM cDNAarchive kit in $0.2 \mathrm{ml}$ microfuge tubes. The reaction mixture of $20 \mu \mathrm{l}$ contained $0.2 \mu \mathrm{g}$ total RNA, $10 \times$ RT buffer, $25 \times$ dNTP mixture, $10 \times$ random primers, MultiScribe RT $(50 \mathrm{U} / \mu \mathrm{l})$ and RNase free water. The cDNA synthesis reactions were carried out at $25^{\circ} \mathrm{C}$ for 10 minutes and $37^{\circ} \mathrm{C}$ for 2 hours using an Eppendorf Personal Cycler. Total cDNA synthesis was performed using ABI PRISM cDNA Archive kit. Real-Time PCR assays were performed in 96-well plates in ABI 7300 Real-Time PCR instrument (Applied Biosystems). PCR analyses were conducted with gene-specific primers and fluorescently labelled Taqman probes of HIF $1 \alpha$. Endogenous control ( $\beta$-actin) was labelled with a report dye (VIC). The real-time data were analyzed with Sequence Detection Systems software version 1.7. All reactions were performed in duplicate. The $\Delta \Delta \mathrm{CT}$ method of relative quantification was used to determine the fold change in expression.

\subsection{Statistics}

Statistical evaluations were done by ANOVA using InStat (Ver.2.04a) computer programme. Graphs were made using SIGMA PLOT (Ver. 2.03, Jandel GmbH, Erkrath, Germany). Relative Quantification Software was used for analyzing Real-Time PCR results.

\section{$3 \quad$ Results}

\subsection{Body Weight of Control and Experimental Rats}

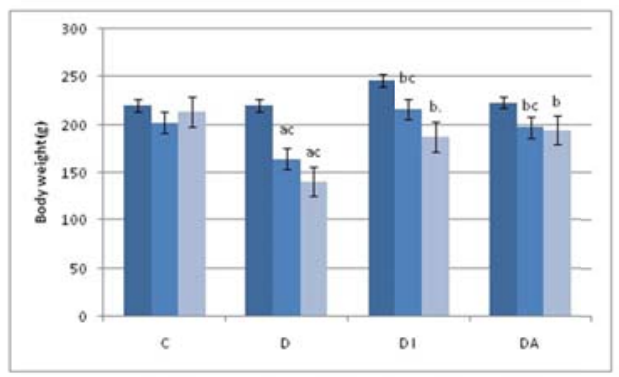

Figure 1: Body weight of control and experimental rats. Values are mean \pm S.E.M of 3-4 separate experiments. Each group consists of $3-4$ rats. ${ }^{\mathrm{a}} \mathrm{p}<0.001$ when compared with control, ${ }^{\mathrm{b}} \mathrm{p}<0.001$ when compared with diabetic group; ${ }^{\mathrm{p}}<0.001$ when compared with initial weight. 
The body weight was significantly decreased $(\mathrm{p}<0.001)$ in STZ induced diabetic rats. Insulin and Aegle marmelos leaf extract treatment significantly $(\mathrm{p}<0.001)$ reversed the body weight when compared to diabetic group.

\subsection{Blood Glucose Level of Control and Experimental Rats}

Blood glucose level of all rats before STZ administration was within the normal range. Streptozotocin administration led to a significant increase $(p<0.001)$ in blood glucose level of diabetic group when compared to control. Decrease in serum glucose from the $6^{\text {th }}$ day onwards may be due to the regeneration of $\beta$ cells of the pancreas, which was destroyed by STZ. Treatment using insulin and Aegle marmelos leaf extract were able to reduce $(\mathrm{p}<0.001)$ the increased blood glucose level significantly when compared to diabetic rats (Table-1).

Table 1: Blood glucose level of control and experimental rats. ${ }^{\mathrm{a}} \mathrm{p}<0.001$ when compared with control, ${ }^{\mathrm{b}} \mathrm{p}<0.001$ when compared with diabetic group; ${ }^{c} \mathrm{p}<0.001$ when compared with initial reading.

\begin{tabular}{|c|l|l|l|l|l|}
\hline $\begin{array}{l}\text { Experimental } \\
\text { groups }\end{array}$ & $\begin{array}{l}0^{\text {th }} \text { Day Before } \\
\text { STZ } \\
\text { injection }\end{array}$ & $\begin{array}{l}3^{\text {rd }} \text { day } \\
\text { (Initial) }\end{array}$ & $6^{\text {th }}$ day & $10^{\text {th }}$ day & $\begin{array}{l}1^{\text {th }} \text { day } \\
\text { (Final) }\end{array}$ \\
\hline C & $88.25 \pm 1.10$ & $89.33 \pm 4.50$ & $88.41 \pm 0.80$ & $103.26 \pm 2.10$ & $99.13 \pm 0.90$ \\
\hline D & $79.14 \pm 1.70$ & $257.13 \pm 0.40^{\mathrm{a}}$ & $288.72 \pm 0.90^{\mathrm{a}}$ & $305.10 \pm 0.40^{\mathrm{a}}$ & $309.96 \pm 1.10^{\mathrm{a}}$ \\
\hline DI & $96.09 \pm 0.70$ & $262.36 \pm 4.80^{\mathrm{a}}$ & $310.41 \pm 0.70^{\mathrm{a}}$ & $212.80 \pm 1.30^{\mathrm{b}, c}$ & $158.00 \pm 1.60^{\mathrm{b}, c}$ \\
\hline DA & $106.09 \pm 0.70$ & $272.36 \pm 3.50^{\mathrm{a}}$ & $321.41 \pm 2.90^{\mathrm{a}}$ & $228.40 \pm 7.40^{\mathrm{b}, c}$ & $168.00 \pm 5.60^{\mathrm{b}, c}$ \\
\hline
\end{tabular}

\subsection{Total Antioxidant Level in the Liver of Control and Experimental Rats}

There was a significant decrease $(\mathrm{p}<0.001)$ in the antioxidant level in the liver off diabetic group when compared to control (Figure-2). This can lead to an increased oxidative stress in the liver tissue of diabetic rats. Treatment with insulin and Aegle marmelos leaf extract increased the levels of antioxidant when compared to diabetic rats.

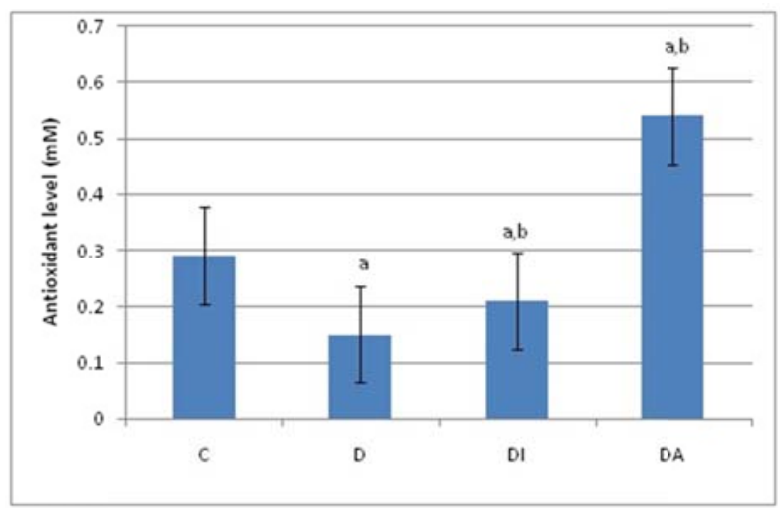

Figure 2: Total antioxidant levels in the liver of control and experimental rats. Values are mean \pm S.E.M of 3-4 separate experiments. Each group consists of $3-4$ rats. ${ }^{a} \mathrm{p}<0.001$ when compared with control, ${ }^{b} \mathrm{p}<0.001$ when compared with diabetic group. 


\subsection{Peroxide Level in the Liver of Control and Experimental Rats}

Diabetic rats showed a significant increase $(\mathrm{p}<0.001)$ in hepatic peroxide level compared to control. Insulin and Aegle marmelos treatment significantly reversed $(\mathrm{p}<0.001)$ the elevated peroxide level when compared to diabetic group. (Figure-3)

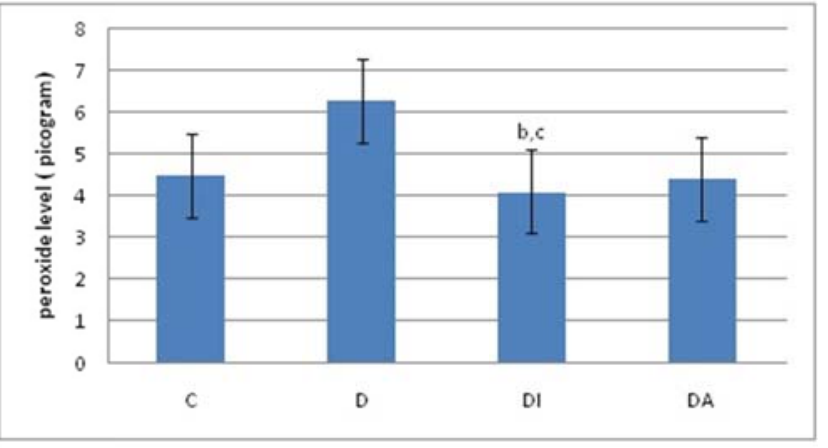

Figure 3: Peroxide level in the liver of control and experimental rats. Values are mean $\mathbb{E}$ S.E.M of 3-4 separate experiments. Each group consists of $3-4$ rats. ${ }^{a} \mathrm{p}<0.001,{ }^{b} \mathrm{p}<0.01$ when compared with control, ${ }^{\mathrm{c}} \mathrm{p}<0.001$ when compared with diabetic.

\subsection{Real time PCR Analysis of HIF-1 $\alpha$ mRNA from the Liver of Control and Experimental Rats}

Real-time PCR gene expression of HIF-1 $\alpha$ showed a significant up regulation $(\mathrm{p}<0.001)$ in the liver of diabetic rats compared to control. There was a significant reversal $(\mathrm{p}<0.001)$ in HIF-1 gene expression in insulin and Aegle marmelos treated rats when compared to diabetic rats (Figure-4 A, B).
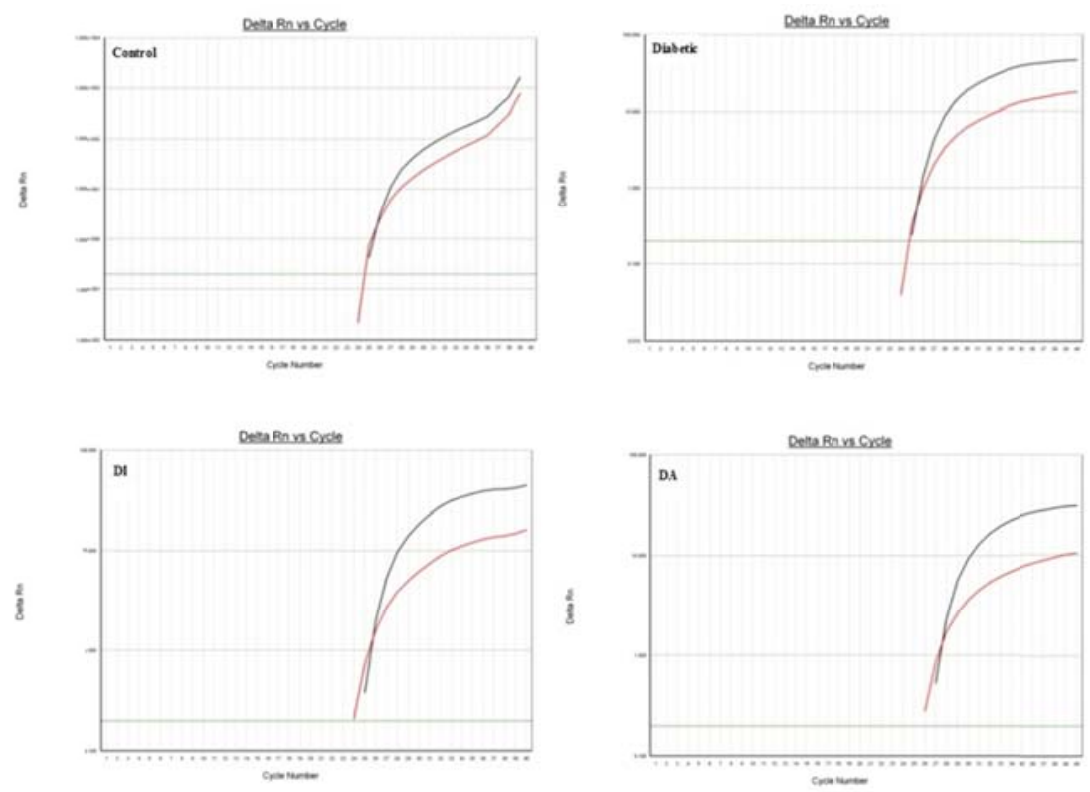

Figure 4A: Representative amplification plot of HIF-1 a mRNA in the liver of control and experimental rats. Red line indicates the graph representing the amplification of housekeeping gene ( $\beta$ - actin) and Black line indicates the graph representing the amplification of HIF-1 gene. Black line indicates the crossing threshюld (Ct) of the samples. $\mathrm{Ct}$ value represents the cycle number at which fluorescence crosses the set threshold. 


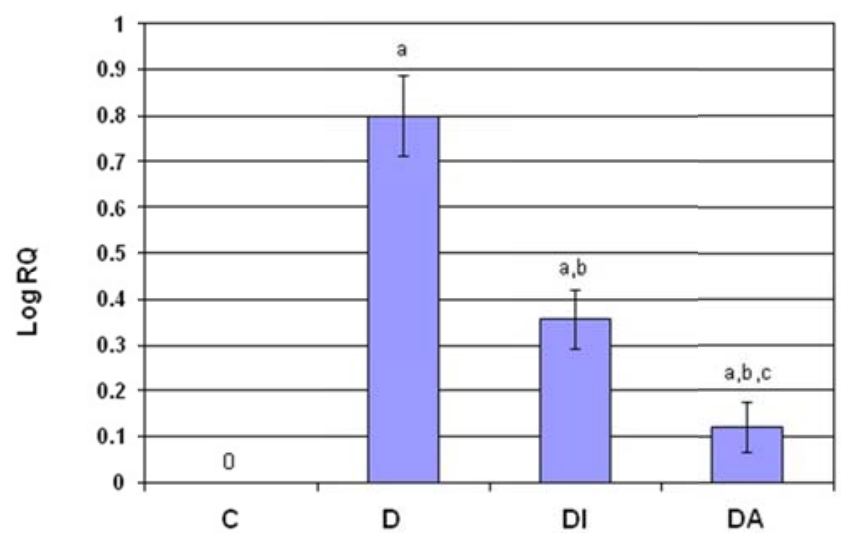

Figure 4B: Real time PCR analysis of HIF-1 a mRNA in the liver of control and experimental rats. The $\Delta \Delta$ CT method of relative quantification was used to determine the fold change in expression. The relative ratios of mRNA levels were calculated using the CT method normalized with $\beta$-actin. CT value as the internal control and Control CT value as the caliberator. PCR analyses were conducted in the liver with gene-specific primers and fluorescently labelled Taqprobe Rn_00577560_m1 HIF 1 a .

\section{Discussion}

In the present study, the observed hyperglycemia and decreased body weight during diabetes are in agreement with the previous reports [20]. Earlier studies reported that the excessive breakdown of tissue proteins can contribute to decrease in body weight of diabetic rats [21]. Aegle marmelos leaf extract treated groups showed a significant increase in body weight compared to diabetic rats. The effect of Aegle marmelos treatment in glycemic control might be due to elevated secretion of insulin from the existing $\beta$-cells, which, in turn, increases the utilization of glucose by the tissue. Aegle marmelos can activate glucose transport in PI3 kinase-dependent fashion [22]; thereby rendering the capability to regulate the glycemic level in the body.

We observed a significant decrease in hepatic antioxidant level and a significant increase in peroxide level in diabetic group. Free radicals play an important role in the causation and complications of diabetes mellitus (Mohamed et al. 1999). Free radicals react with lipids and cause peroxidative changes that result in enhanced lipid peroxidation [23]. Studies by Karpen et al. [24] also reported an elevated lipid peroxide level in the plasma of Streptozotocin diabetic rats. Various tissues are prone to oxidative damage which can cause diabetes complications, implying that, the restoration of antioxidant status is an important parameter to evaluate the effect of antidiabetic compound.

Our study showed a prominent reversal in the level of antioxidants suggesting the remarkable potential of Aegle marmelos in alleviating oxidative stress in diabetes. The significant decline in the peroxide level in the liver tissue of A. marmelos treated diabetic rats indicate that Aegle marmelos extract effectively increased antioxidant potential in vivo. Oxidative stress plays a pivotal role in the development of diabetes complications, both microvascular and cardiovascular complications [25]. The elevated antioxidant level coupled with the reduced aqueous peroxides in the liver of treatment group points to the antioxidant property of Aegle marmelos leaf extract.

In the present study, we also observed an up regulation in the expression of HIF-1 gene in diabetic rats. Studies by Catrina et al. [26] showed that hyperglycaemia interferes with protection from proteasome-mediated degradation of HIF-1. Hypoxia inducible factor-1 (HIF-1) is a transcription factor that is essential for adaptive responses of the cell to hypoxia. HIF - 1 is up regulated during oxidative stress which also increases the level of reactive oxygen species [27]. The increased HIF expression can augment the oxidative stress of the liver by elevating the levels of ROS. The treatment with Aegle marmelos leaf extract was also found to regulate the HIF expression thereby encountering the oxidative stress in multiple levels. Natural antioxidants like Aegle marmelos can strengthen the endogenous antioxidant defenses from reactive oxygen species and restore and optimal balance by neutralizing the reactive species. The present study clearly indicated that Aegle marmelos could prartially overcome the 
diabetes related complications in liver by restoring its antioxidant capability and reducing the oxidative stress.

\section{Conclusion}

The ameliorating effects of Aegle marmelos leaf extract in the elevated peroxide level and HIF expression and diminished antioxidant level were observed in the present study. Natural antioxidants might have strengthened the endogenous antioxidant defenses from reactive oxygen species and restored the optimal balance by neutralizing the reactive species. Taking into consideration of the anti hyperglycemic effect and antioxidant effects of Aegle marmelos leaf extract, it can be considered as an alternate herbal medicine to compact diabetes, with potential to prevent diabetes related complications to other tissues.

Acknowledgement. Anju T R thanks DBT, Govt of India for DBT Research Associateship. The authors declare that there is no conflict of interest that could be perceived as prejudicing the impartiality of the research reported.

\section{References}

1. B. Jayakar and B. Suresh, "Anti hyperglycemic and hypoglycemic effect of Aporosalindleyana in alloxan-induced diabetic rats," Journal of Ethnopharmacology, vol. 84, pp. 247-249, 2003.

2. J. L. Evans, I. D. Goldfine, B. A. Maddax, and G. M. Grodsky, "Are oxidative stress -activated signaling pathway mediators of insulin resistance and beta cell dysfunction?," Diabetes vol. 52, pp. 1-8, 2003.

3. J. L. Evans, I. D. Goldfine, B. A. Maddux, and G. M. Grodsky, "Oxidative stress and stress-activated signaling pathways: a unifying hypothesis of type 2 diabetes," Endocr Rev, vol. 23, pp. 599-622, 2002.

4. R. L. Wilson. "Free radicals and tissue damage, mechanistic evidence from radiation studies," in Biochemical mechanisms of Liver Injury. New York, Academic Press, pp. 123-125, 1998.

5. R. Harini and K. V. Pugalendi, "Antioxidant and anti hyperlipidaemic activity of protocatechuic acid on Streptozotocin-diabetic rats research gate," Redox Rep., vol. 15, pp. 71-80, 2010.

6. D. Jay, H. Hitomi, and K. K. Griendling, "Oxidative stress and diabetic cardiovascular complications," Free Rad Biol Med, vol. 40, pp. 183-92, 2006.

7. E. Wright, J. L. Scism-Bacon, and L. C. Glass, "Oxidative stress in type 2 diabetes: the role of fasting and postprandial glycemia," Int J ClinPrac, vol. 60, pp. 308-14, 2006.

8. G. L. King, and M. R. Loken, "Hyperglycemia-induced oxidative stress in diabetic complications," Histochem Cell Biol, vol. 122, pp. 333-338, 2004.

9. J. W. Boynes. "Role of oxidative stress in development of complication in diabetes," Diabetes, vol. 40, pp. 405411, 1991.

10.A. P. Zou, and A. W. Cowley Jr, "Reactive oxygen species and molecular regulation of renal oxygenation," Acta Physiol Scand, vol. 179, pp. 233-241, 2003.

11.J. J. Bullock, S. L. Mehta, Y. Lin, P. Lolla, and P. A. Li, "Hyperglycemia-enhanced ischemic brain damage in mutant manganese SOD mice is associated with suppression of HIF-1alpha," Neurosci Lett, vol. 456, pp. 89-92, 2009.

12.R. Marfella, M. D'Amico, C. Di Filippo, E. Piegari, F. Nappo, K. Esposito et al, "Myocardial infarction in diabetic rats: role of hyperglycaemia on infarct size and early expression of hypoxia-inducible factor 1," Diabetologia, vol. 45, pp. 1172-1181, 2002.

13.G. Papaccio, F. A. Pisanti, M. V. Latronico, E. Ammendola, and M. Galdieri, "Multiple low-dose and single high-dose treatments with streptozotocin do not generate nitric oxide," J Cell Biochem, vol. 77, pp. 82-91, 2000.

14.V. Sanchez-Valle, N. C. Chavez-Tapia, M. Uribe, and N. Mendez-Sanchez, "Role of oxidative stress and molecular changes in liver fibrosis: A review," Curr. Med. Chem, vol. 19, pp. 4850-4860, 2012.

15.M. C. Sabu, and R. Kuttan, "Antidiabetic activity of Aeglemarmelos and its relationship with its antioxidant properties," Indian J Physiol Pharmacol, vol. 48, no. 1, pp. 81-88, 2004. 
16.P. T. C. Ponnachan, C. S. Paulose, and K. R. Panikkar, "Effect of leaf extract of Aegle marmelos in diabetic rats," Indian Journal of Experimental Biology, vol. 31, pp. 345-347, 1993.

17.J. K. Grover, S. Yadav, and V. Vats, "Medicinal plants of India with anti-diabetic potential," J Ethanopharmacol, vol. 81, pp. 81-100, 2002.

18.A. V. Das, P. S. Padayatti, and C. S. Paulose, "Effect of leaf extract of Aeglemarmelos (L.) Correa ex Roxb on histological and ultra structural changes in tissues of Streptozotocin induced diabetic rats," Indian Journal of Experimental Biology, vol. 34, pp. 341-345, 1996.

19.O. H. Lowry, N. J. Roserbrough, A. L. Farr, and R. J. Randall, "Protein measurements and folin phenol reagent," J Biol Chem, vol. 193, pp. 265-275, 1951.

20.A. Junod, A. E. Lambert, W. Staufferacher, and A. E. Renold, "Diabetogenic action of Streptozotocin: Relationship of dose to metabolic response," J. Clin. Invest, vol. 48, pp. 2129-2139, 1969.

21.M. Salahuddin and S. S. Jalalpure, "Anti diabetic activity of aqueous fruit extract of CucumistrigonusRoxb. in Streptozotocin- induced-diabetic rats," J Ethno pharmacol, vol. 127, no. 2, pp. 565-567, 2010.

22.R. Anandharajan, S. Jaiganesh, N. Shankernarayanan, R. Viswakarma, and A. Balakrishnan, "In vitro glucose uptake activity of Aegle marmelose and Syzygiumcumini by activation of Glut-4, PI3 kinase and PPARY in L 6 myotubes," Phytomedicine, vol. 13, pp. 434-441, 2006.

23.M. W. Girotti, "Mechanisms of lipid peroxidation," Free RadicBiolMed, vol. 1, pp. 87-95, 1985.

24.C. W. Karpen, K. A. Pritchard, A. J. Merola Jr., and R. V. Panganamala, "Alterations of the prostaglandin thromboxane ratio in streptozotocin induced diabetic rats," ProstaglandLeukotrienMed, vol. 8, pp. 93-103, 1982.

25.F. Giacco, and M. Brownlee, "Oxidative Stress and Diabetic Complications," Circ Res, vol. 107, no. 9, pp. 105870, 2010.

26.S. B. Catrina, K. Okamoto, T. Pereira, K. Brismar, and L. Poellinger, "Hyperglycemia Regulates HypoxiaInducible Factor- $1 \alpha$ Protein Stability and Function," Diabetes, vol. 53, pp. 3226-3232, 2004.

27.T. R. Anju, and C. S. Paulose, "Amelioration of hypoxia-induced striatal 5-HT(2A) receptor, 5-HT transporter and HIF1 alterations by glucose, oxygen and epinephrine in neonatal rats," Neuroscience letters, vol. 502, no. 3, pp. 129-132, 2011. 